\title{
Across Disciplines: Triggering Frame Awareness in Design Education
}

\author{
Gregory A. Luhan \\ University of Kentucky, USA \\ gregory.luhan@uky.edu \\ Texas A\&M University, USA \\ gluhan@arch.tamu.edu
}

\author{
Robert Gregory \\ University of Kentucky, USA \\ Robert.Gregory@uky.edu
}

\begin{abstract}
Tacit knowledge is paradoxical: something we know yet don't know we know, knowledge we sense but can't articulate. In Polanyi's definition of tacit knowledge, "we know more than we can say" (1966/2009; Scott, 1985; Gelwick, 1977). It's important to see that tacit knowledge is part of a sequence; mental structures, in awareness when first learned, eventually become tacit, operating thenceforth as unquestioned assumptions. These tacit structures pose a problem for professional education in disciplines that encourage creativity. This paper examines the design and re-design of an interdisciplinary course intended to help make these tacit structures visible, to trigger frame awareness.
\end{abstract}

Keywords: Tacit knowledge; Design thinking; Sustainability; Systems thinking; Frame reflection.

\section{Introduction}

Tacit cognitive structures have been explored by many disciplines (cognitive science, anthropology, psychology) under several names: frames, schemas, and scripts (D'Andrade, R., 1992; D'Andrade, R. and Strauss, C., 1992; Mandler, J., 1984). Although useful in automating routine repetitious activity, their tacit nature makes them problematic for disciplines that emphasize creative activity. Put another way, it's difficult to think outside the box if the box is invisible. As Schön (1983) explains, such frames limit creativity because they determine our strategies of attention. Frames shape thought and also behavior but invisibly; practitioners "do not attend to the ways in which they construct the reality in which they function; for them, it is simply the given reality." Bijker (1989) has called such mental structures technological frames "constructed from the concepts and techniques used by a community in its problem solving" -- defined broadly to include "a combination of current theories, tacit knowledge, engineering practice (such as design methods and criteria)" etc. The more advanced the practitioner, the more tacit the knowledge, as Lindblom and Cohen (1979) put it: "all expertise rests on a veritable iceberg of tacit, taken-for-granted knowledge."

\section{Frame reflection and back talk}

In a more recent work, Schön and Rein (1994), the authors study policy and regulations considered as designed objects. Here they foreground the social dimension of design and problem-solving. Frame awareness comes about through resistance and conflict: "We discover our frames in becoming aware of what resists them." Comparing the creation and rollout of a policy to a conversation, they term the resistance back talk. For example, in one case the back talk was a refusal of the users to adopt a new campus computing arrangement in the ways intended; in another, back talk appeared when users found loopholes to exploit, which distorted the policy in negative ways. What's important here is not the resistance per se but what policy designers do in response to it. A poor response would consider the users mistaken or ignorant and simply change the marketing to make the policy more palatable. A more productive response is to use the back talk as an opportunity to learn by becoming aware of the frames involved and then by reframing the policy design. Schön and Rein summarize the case study's lesson this way: "they learned that they must think differently about the very meaning of the problem of homelessness." This paper will suggest that syllabus design is similar to policy design and can also benefit from frame awareness developed through the proper response to back talk.

\section{Inducing frame awareness through course design}

Although disciplinary/professional frames are useful and a goal that students work hard to reach, they also function as blinders when tacit. For teachers of undergraduates, frame awareness is a desirable goal but a task to be approached carefully and by design.

In addition to a professional discipline-specific frame, students will operate within an educational frame or frames. Given that they will have spent roughly two decades learning strategies about getting good grades, framing -- these assumptions -- are by junior year tacit and unexamined. Studies have shown that what is being tested and how it is graded is the most powerful determiner of the frame adopted. Students analyze the way they will be graded and react accordingly, adopting a superficial rote memorization frame 
when that seems most practical and a more integrative deep learning frame when course design encourages that (Martone, Hounsell, and Entwistle, 1984).

In addition to assessment/evaluation design, course design can promote frame awareness by structuring the course for crossdisciplinary teams, a situation in which frame awareness is not demanded explicitly by the instructor but arises out of necessity as a pragmatic approach to back talk within teamwork. The optimal learning response to back talk in this context is attempting to become aware of and then to articulate one's tacit assumptions about goals and appropriate processes. This kind of communication is unnecessary when the practitioner is working with others who share the same tacit assumptions. Thus the value of working with multiple disciplines (Adams et al, 2009) is an experience that also engages the social nature of frame awareness. In other words, frames tend to be invisible to introspection but can come to light in discussion with others. What's lacking in introspection is the kind of resistance that prompts frame awareness.

An example of this course design is "Systems Thinking for Sustainability" (STFS), discussed in the next section.

\section{"Systems Thinking for Sustainability"}

"Systems Thinking for Sustainability" (STFS) is an educational research project intended to contribute to science, technology, engineering and mathematics (STEM) education for undergraduates that started in 2011-2012 (Badurdeen et al, 2012; Badurdeen et al, 2013). The project, a three-year effort, involves creating, implementing, assessing, and refining a course called "Systems Thinking for Sustainability." Faculty from several disciplines at the University of Kentucky (UKY) -- engineering, design/architecture, business \& economics, and education -introduce students to systems and sustainability concepts and tools; students are then challenged to investigate, create, exchange, and integrate these tools in team projects that have a local focus but also have global implications that address the transition to sustainability (NRC, 1999).

The STFS project grew out of a problem: by the time seniors in several disciplines reached a capstone or senior design course, they had become so successfully educated in their disciplinary framework that they found it difficult to work with anyone outside their frame and were unable to see problems other than how their discipline saw them. At the same time faculty were unhappy about the fragmented, sometimes simplistic way sustainability was being taught, if it was being taught at all. Sustainable development, a looming issue of great complexity that demands an interdisciplinary approach, was selected as a general topic area. Developing a holistic course based that encouraged and enabled systems thinking (in this case, system dynamics) was seen as a useful way to investigate sustainability while at the same time, the team noted that it was also an opportunity to give the students a common language for collaboration (Forrester, 1968; NRC, 1996; Meadows, 2008). The four disciplines teamed for the project saw that sustainability problems could be addressed from a systems perspective and thus used inclusive educational models that included design thinking.

\section{Design thinking for STFS design}

Cross (2007) offers a useful if simplified contrast: science proceeds by analysis and design proceeds by synthesis. That is, where a scientist would approach the solution to a issue by systematically exploring the problem, assuming the best solution will come from the most thorough analysis, a designer would get a sense of the problem and then offer a series of solutions. In this way design thinking can be described as "fail fast, fail often" -- quickly sketching solutions and eliminating the unworkable ones. Where a scientist assumes the solution is "there" in the problem and can be found by analysis, the designer works in a more abductive way and assumes that a workable solution constitutes sufficient understanding of the problem. A common example is prescribing a medication to determine the nature of the disease; if the disease is cured by a particular medicine, that cure indicates what the disease was and makes further exploration moot. More specifically, Cross suggests that design thinking is a form of pattern making: "the designer learns to think in this sketch-like form, in which the abstract patterns of user requirements are turned into the concrete patterns of an actual object." That is, the difference between science and design is the difference between finding and making.

Thus, according to Cross, design thinking is useful for "resolving illdefined problems" like the so-called "wicked problems" (Rittel and Webber, 1973) for which all variables can never be known and which involve policy issues and moral/religious/ethical values outside the realm of scientific problem-solving but can be rendered moot by an effective solution. Since many of the most vexing sustainability problems are "wicked" in this sense, including designers in the course was a way to provide a path toward a solution that might be different from an engineering solution; since engineering takes a scientific approach and can also take a design-like approach on occasion, it was thought that these disciplines would be different yet compatible. Students from marketing were included to provide an example of problemsolving that is focused outward to the needs and characteristics of the intended customer without regard to technical issues. Students from Math Education were included to provide an introspective focus toward the teams; they would be concentrated on the problem-solving process and would therefore be equipped by training to facilitate discussion and more effective communication. 
The STFS course was designed to raise these issues for enhanced student reflection even though: (1) problem-solving and problemframing methods differ, sometimes radically; (2) these methods involve assumptions, constructs, and models that are human creations that approximate but never substitute for the realities they model, and (3) learning is in great part a process of discovering and examining one's assumptions (and those of others).

\section{Course Syllabus (Initial Design, 2011-2012)}

The initial course design framework structured learning in two parts: the first, led by faculty, provided concepts, strategies, tactics, tools, and assignments to equip students for team projects; and the second, led by student teams, worked with drafts of product designs aimed at sub issues within an umbrella project: Campus Living. In part one, all instructors attended the class sessions, but individual instructors took turns leading the presentations. Each discipline provided concepts and tools; for example, architecture provided an iterative design-thinking framework. Presentation topics included innovative "green" building designs and case studies where a business or industry struggled with sustainability issues. After each presentation, students responded to the issue or were asked to use the tool presented. Students were paired randomly to respond to the weekly assignments; the duos changed for each assignment, which tasked students to define a system, to communicate that system simply and clearly in narrative form, to present the system as a short public service announcement (PSA), and to employ modeling software (Vensim) to analyze system behavior and performance such as stocks, flows, feedback loops, and delays. In part two, roughly midway through the semester, the students were assigned to teams containing at least one member from each discipline. The student teams chose an issue and began work. Their choices were constrained only by the need to address Campus Living and to use systems thinking to explore sustainability aspects of their project.

Campus Living was chosen to provide real world problems that affected daily existence. For example, one project identified a problem with traveling across campus inexpensively and efficiently; alternatives (automobiles, campus shuttle service, rental bicycles) were assessed for convenience, cost to students and to the university, resources use, health/safety of students and the larger community and environmental impacts.

The course objectives precluded tests and final exams as counterproductive, because they encouraged memorization instead of developing student problem-solving experience. Alternatively, the performance evaluation was based upon the Campus Living projects as presented by the teams at a Universitywide project review showcase. During this event, the students presented their findings, proposed solutions, and lessons learned using posters, brochures, PowerPoint slides, and Public Service
Announcements, all of which had been critiqued and iterated multiple times in class by the students and the instructors.

\section{Outcomes and Re-Design}

\section{Outcomes of the initial STFS offering}

To no experienced teacher's surprise, the first iteration (Spring 2012) revealed a number of areas for improvement. Aside from the typical logistical issues that arise in any new course, the instructors were surprised and taken aback by the level of conflict and back talk among both the faculty team and the students that arose out of teamwork. For example, there was conflict about the expectations for how much and what level of work students could be expected to do, based on disciplinary frames. One discipline's rigor was another's unrealistic expectations. Students in turn were upset by what they saw as disorder since their frame for how a course should work did not focus on more traditional lectures with tests and memorization, but rather included problem-based design approaches. The difficulty at this stage centered on disagreements were too often seen as personal; meaning that the disciplinary frames in operation were not visible right away. That is, it was not really this person's expectations but the expectations of his/her discipline.

\section{Back Talk}

In time, faculty understood that these conflicts constituted evidence of a process of frame awareness and to some extent, frame reflection. The heat of the conflict was in fact more evidence that tacit frames were in conflict, as Garfinkel saw in his so-called breaching experiments. These involved one person in a dialogue refusing to play the expected role in an everyday scenario. For example, instead of responding to the question "how are you?" with "fine," the person questioned would ask in what sense the question was meant - how am I financially, emotionally, physically? At this point the first person would be so taken aback by resistance that he/she typically lose his/her temper and stalk off. Garfinkel understood these reactions as a sign of how much tacit material (unexamined assumptions and expectations here) is involved in routine communication and how unpleasant the moment of frame awareness can be (Heritage, 1984). The point is, whose frame awareness? In his experiments the observer (Garfinkel) and the subject's acquaintance who had agreed to play the role would see tacit assumptions suddenly become explicit but it's doubtful the subject did so as well. Thus, in STFS, the instructors had to begin the frame awareness process, partly because an aspect of expertise in some disciplines to observe activity prompted by unexamined assumptions and partly because the instructors were anticipating such reactions would take place, though not aware in advance what shape they might take nor that they might occur between instructors as well as between students. 


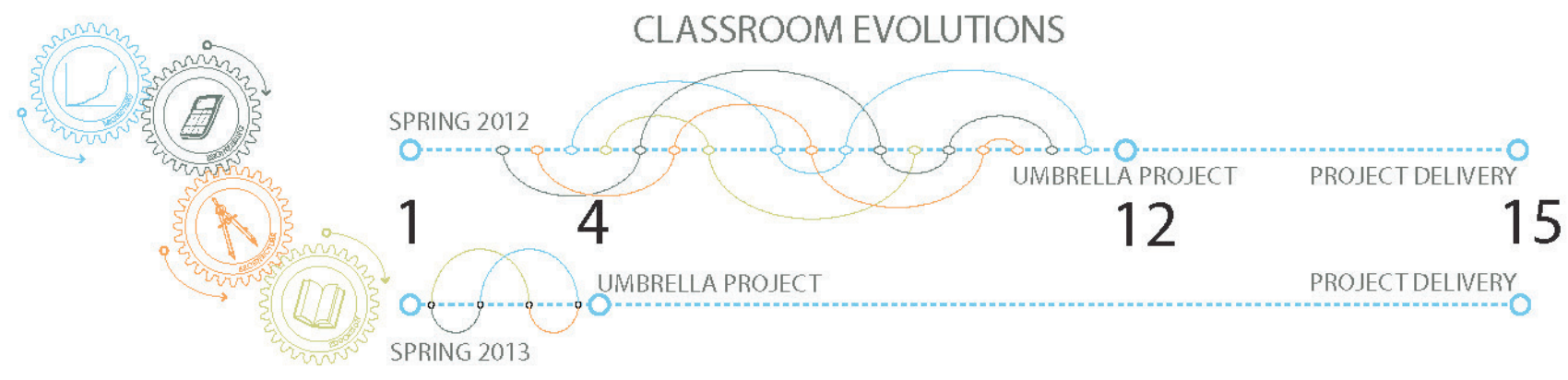

Figure 1: Syllabus outline depicting course delivery changes between Spring 2012 and Spring 2013 and the discipline overlaps while presenting course content.

\section{Syllabus design iteration (2012-2013)}

In response to the first run's backtalk, the instructors re-designed the course. The course had been designed to encourage this by providing many integral feedback loops: from student to instructors via assignments and in-class discussion, from student to student during team activity which was then fed to instructors via TA's, from instructor to instructor via the weekly course meetings during the semester and the biweekly meetings in summer and fall set aside for reflecting on issues and considering re-design. In this way, the instructors used an element of systems thinking and design thinking as well. The goal of the re-design was to address areas of conflict for the students that were not fruitful to the course investigation. At the same time, the re-design gave faculty a way to be aware of and reflect on their own frames. Unfortunately, space does not permit discussion of the redesign. Here we focus on one key area: teamwork.

Co-lecturing was introduced for the second run (2013). That is, presentations previously done independently would now be done by two faculty, who therefore had to work out any disagreements or misunderstandings issues in advance: what the content would be, what would be emphasized, and so forth. Although this approach involved more work, the preparatory discussions helped faculty understand and appreciate each other's areas of expertise and clarify where the areas of real disagreement were (as opposed to apparent disagreements arising from different academic cultures etc.). In this way, re-design worked enabled frame awareness prompted by back talk from the first run, which then led to frame reflection that informed the re-design in the second run. At the same time, material was added to ensure students could see how teamwork could be a potential problem to that needed to be addressed as part of the course work; students were briefed on the types of difficulties to expect and were given strategies for coping with them. To reinforce the importance of the topic, instructors made themselves available for coaching on team issues such as free riders.

Lastly, because the university is currently in the process of redesigning its campus, it was possible to invite the Vice-President for Facilities and members of the architectural firm to give presentations to the class. Student questioning about the minimal attention to sustainability as a design parameter generated a lively and sometimes heated back-and-forth. Students later commented that the presenters seemed constrained by their professional job roles and were thus missing valid and, to them, obvious design options. In other words, students had a vivid example of the way frames can constrain one's thinking without the frames themselves being evident to the one constrained.

\section{Conclusion}

It may seem perverse to deliberately design something intended to provoke conflict but the desirable learning outcomes that frame awareness and reflection bring -- a strong basis for critical thinking, for example were valuable enough to make this approach worth exploring. Re-design did not eliminate possible fruitful points of conflict and disagreement but did eliminate unfruitful conflict, such as by dropping the use of additional software when it was found to be a burden that didn't really add value. Thus, the re-design did not eliminate all team disagreements but did supply tools to help the team respond to back talk effectively. In addition, co-lecturing meant students -- including the graduate students who worked closely with the instructors -- could witness the process of negotiating disagreements. It was clear from the student's exit interviews that this re-design had a profound impact on improving student teamwork. This was also clear from the very different classroom atmosphere in the second run and from other indicators, such as a request by one team, strangers before the course, who wanted to continue to develop their proposed software application or app well beyond the end of the semester. A final clear lesson learned: students benefited from an example of someone else being constrained by tacit frames, in this case by the Vice-President and his colleagues, because they were a real world example rather than a textbook item.

\section{Acknowledgements}

The National Science Foundation under TUES Grant 1044232 supported this work. Support for Research Assistants Hai Fu and Adam Brown has been provided by the College of Engineering, University of Kentucky. 


\section{References}

Adams R., Mann, L., Forin, T. and Jordan, S. (2009). Cross-Disciplinary Practice in Engineering Contexts DS 58-9: Proceedings of ICED 09, 17th International Conference on Engineering Design, Vol. 9, Human Behavior in Design, Palo Alto, CA, USA, 24.-27.08.

Badurdeen, F., Gregory, R., Luhan, G.A., Schroeder, M., Vincent, L.V and Sekulic, D.P., (2012) Systems Thinking for Sustainability: Envisioning Trans-disciplinary Transformations in STEM Education, International Symposium On Sustainable Systems \& Technology 2012, Boston, MA, May 16-18, 2012, pp. 1-6.

Badurdeen, F., Brown, A., Gregory, R., Fu, H., Schroeder, M.. Sekulic, D. P. Vincent, L. and Luhan, G. A. (2013). Reframing interdisciplinary approaches to systems thinking for sustainability. Proceedings of the International Symposium on Sustainable Systems \& Technologies, ISSST2013, May 15 - 17, Cincinnati, OH USA.

Bijker, W. (1989). The social construction of Bakelite. In W. Bijker, T. Hughes, and T. Pinch (Eds.), Social construction of technological systems: new directions in the sociology and history of technology (pp. 159-187). Cambridge, Mass.: MIT Press.

Cross, N. (2007) Designerly ways of knowing. Basel: Birkhauser.

D'Andrade, R. (1995). The development of cognitive anthropology Cambridge: Cambridge Univ. Press.

D'Andrade, R. and Strauss, C., eds. (1992). Human motives and cultural models. Cambridge: Cambridge Univ. Press.

Forrester, Jay. (1968). Principles of systems. Waltham, Mass.: Pegasus.

Gelwick, R. (1977). The way of discovery: an introduction to the thought of Michael Polanyi. New York: Oxford Univ. Press.

Heritage, J. (1984). Garfinkel and ethnomethodology. Boston: Polity.
Lindblom, C. and Cohen, D. (1979). Usable Knowledge: Social Science and Social Problem Solving. New Haven: Yale Univ. Press.

Mandler, J. (1984). Stories, scripts, and scenes: aspects of schema theory. London: Lawrence Erlbaum.

Martone, F., Hounsell, D. and Entwistle, N., eds. (1984). Experience of learning: implications for teaching and studying in higher education. Edinburgh: Univ. of Edinburgh Centre for Teaching, Learning and Assessment.

Meadows, D. (2008). Thinking in systems: a primer, ed. Diana Wright. White River Junction, Vt: Chelsea Green.

National Research Council. (1999). Our common journey: a transition toward sustainability, Washington, D.C.: National Academies Press. Retrieved from http://www.nap.edu/catalog.php?record_id=9690.

National Research Council. (1996). From analysis to action: undergraduate education in science, mathematics, engineering, and technology. Washington, DC: National Academy Press. Retrieved from http://search.nap.edu/html/analysis/analysis.pdf.

Polanyi, M. (1966; reissue 2009) The tacit dimension. Chicago: Univ. of Chicago Press.

Rittel, H. and Webber, M. (1973). Dilemmas in a general theory of planning. Policy Sciences 4,155-169.

Schön, D. (1983). The reflective practitioner: how professionals think in action. New York: Basic Books.

Schön, D and Rein, M. (1994). Frame reflection: toward the resolution of intractable policy controversies. New York: Basic Books.

Scott, D. (1985). Everyman Revived: The Common Sense of Michael Polanyi. 